RESEARCHARTICLE

\title{
Muslim Parent Preferences for Children's Storybook Illustrations: Cultural Relevance in the Context of the United Arab Emirates
}

\author{
Lydia Barza $^{1 *}$ and Antje von Suchodoletz ${ }^{2}$ \\ ${ }^{1}$ College of Education, Zayed University, UAE \\ ${ }^{2}$ Department of Psychology, New York University Abu Dhabi, UAE
}

\begin{abstract}
Literacy socialization begins at home with books chosen by parents. Using a sociocultural perspective, the purpose of this study was to document Arab, Muslim parents' $(n=118)$ preferences for children's storybook illustrations in the United Arab Emirates. Open-ended questions were analyzed using the constant comparative method. Cultural gender schemes were highlighted. Results imply that some innocuous themes commonly found in storybooks reflecting Western values were perceived as culturally peripheral to parents from a Muslim background. Findings have implications for creating more culturally relevant children's storybooks to improve the quantity and quality of home literacy experiences of Arab, Muslim families.
\end{abstract}

\section{Keywords}

Illustrations; primary education, book selection, cultural content, family literacy, United Arab Emirates

\section{G Open Access}

Citation: Barza, L., von Suchodoletz, A. (2017). Muslim Parent Preferences for Children's Storybook Illustrations: Cultural Relevance in the Context of the United Arab Emirates. Interdisciplinary Education and Psychology, 2(1):2.

Received: August 25, 2017

Accepted: December 05, 2017

Published: December 24, 2017

Copyright: ( 2017 Barza et al. This is an open access article distributed under the terms of the Creative $C$ ommons Attribution License, which permits unrestricted use, distribution, and reproduction in any medium, provided the original author and source are credited.

Corresponding author:

Lydia Barza, College of Education,

Zayed University, United Arab Emirates

E-mail: lydiabarza@hotmail.com

\section{Introduction}

It has been suggested that literacy and identity are social constructions (Lewis \& del Valle, 2009; Moje \& Luke, 2009) with an inextricable relationship to academic learning (Wortham, 2006). The process of literacy socialization begins early in life, influenced first by parents and later by schools (Kraaykamp, 2003; Sénéchal \& LeFevre, 2002). Cultural factors influence the home literacy practices of families, such as the selection of children's storybooks. Far from neutral, children's storybooks are culture laden and reflect the values and beliefs of the source culture (Chick \& Heilman-Houser, 2000; Cochran-Smith, 2001; Schudson, 1989). To illustrate, the Islamic Foundation avoided publishing children's literature that depicted animate beings in the 1980s because Islam forbids image making, drawing or sculpting animate beings (Janson, 2012). Such restrictions were lifted by the late 1990s because many Muslim scholars agreed with the interpretation of sacred texts (the hadith) that there is an exception when it comes to toys and images used to entertain and teach children. Given that imagery in children's literature is central to both the teaching and learning process, it begs the question of how cultural identity influences parents' choices of storybooks for their children.

This paper investigates which types of children's storybook illustrations are accepted and rejected by Muslim nationals living in the United Arab Emirates (UAE), thus contributing to the dearth of book selection literature on Muslim populations. We do this from a sociocultural perspective that offers empirically based information that may be used to promote the creation and use of culturally relevant children's literature in the region.

\section{Theoretical Foundation: Cultural Discontinuity Theory}

Cultural discontinuity theory is derived from the concept of cultural capital and social reproduction accentuated by Bourdieu and Passeron (1990) and others (e.g., Coleman, 1988; Freire, 1973; Sue \& Sue, 2003). The basic assumption is that existing discrepancies between 
social systems have overarching influences on the social, economic and political fate of community members. For example, discrepancies between the cultures of children at home and that of their schools are highlighted because these discrepancies may result in power differentials and subsequent devaluation of particular cultures in schools (Ndura, 2004; Parsons, Travis, \& Simpson, 2005; Webb-Johnson, 2003). Although these discontinuities between school and home are most often described in the literature as being pronounced for ethnic minority groups in the U.S. (Gay, 2000; Goldenberg et al., 1992; Ladson-Billings, 1994; Nieto, 1999), we argue that the notion is relevant in the UAE educational setting with reference to the local Emirati population.

For Arab cultures with a strong emphasis on oral tradition, reading to children or encouraging children to read outside of school is not considered common (Mdallel, 2010). However, today's classroom practices in the UAE reflect mainstream cultural values that represent Western norms. This is because the majority of teachers in the country are culturally foreign and non-local (Badri et al., 2011). In addition, much of the children's literature used is in English, since schools have shifted from Arabic to English as a medium of instruction. As such, there is a cultural mismatch between home and school consistent with what is described in much of the literature in the West (Sue \& Sue, 2003). As such, the influx of mostly Western teachers can be assumed to influence parents' perceptions of children's literacy over time (Barza, 2017). Nevertheless, parents' preferences regarding children's storybook selection is limited and their illustration preferences have not yet been documented within the UAE. This type of systematic, descriptive study is valuable because it provides educators with local knowledge helping to avoid making assumptions about families' values that may negatively influence opportunities to learn (Wortham, 2006).

\section{Impact of Cultural Incompatibility on Home Literacy Practices and School Achievement}

Early literacy experiences with parents, even before formal schooling begins, have an important impact on future academic achievement (Burchinal et al., 2011; Hale et al., 2011). An important, though understudied, aspect of home literacy practices is parents' selection of storybooks. For example, Barza (2014) found that Jamaican-American families, unlike the Cuban-American and Haitian-American ethno-cultural groups they were compared to, preferred Bible-based storybook materials for their children as consistent with their cultural and religious values. Goldenberg et al. (1992) revealed that the family literacy context even affected the use of school-provided materials, since their Hispanic participants did not use materials provided in ways that were intended by the school. Therefore, if parents are not attracted to children's storybooks commercially available to them or those available from their children's schools, then they might be less likely to engage in joint storybook reading or other book-based practices that enhance early literacy learning.

Consistent with this assumption, cultural incompatibility has been used to explain discrepancies in academic achievement (Sue, 2004; Tyler et al., 2008). Persistent misunderstandings due to differing expectations and socialization practices pose a challenge to students' success in school (Bourdieu \& Passeron, 1990; Hauser-Cram et al., 2003; Sue \& Sue, 2003; Tyler, Boykin, \& Walton, 2006). In contrast, children benefit from the integration of their families' 'funds of knowledge' in the curriculum because they are easy to relate to, foster pride, increase student motivation, and build on that with which they are already familiar (Howard, 2010; Moll \& Gonzalez, 1994). There is some evidence from the U.S. that children's school achievement improves when the teaching pedagogy and resources used are more culturally relevant with Hispanic (Goldenberg, 1989), African-American (Boykin \& Cunningham, 2001; Ladson-Billings,1994), Native Hawaiian (Vogt, Jordan, \& Tharp, 1987), and Native American families (Jordan et al., 1985). For example, the evaluation of a culturally compatible language arts program for Hawaiian children showed that when teachers were provided with information on the home culture of children, their effort to integrate the culturebased practices of Native Hawaiian families resulted in achievement gains (Tharp, 1982). However, the very same program used with another ethno-cultural group was not as successful (Jordan et al., 1985). It can therefore be assumed that reading materials affect their subsequent use, which in turn varies among cultural groups.

In accordance with the conceptual model of cultural discontinuity proposed by Tyler and colleagues (2008), the value-based behaviors at home that are related to children's storybook selection may be antithetical to those of the Western influenced mainstream school culture in this context. Nevertheless, there is a lack of research looking specifically at the content or 
illustrations of the storybooks used for instruction at school or at home. Few examine genre and/or illustration preference (Brookshire et al., 2002; Chapman et al., 2007; Mohr, 2003; Saracho \& Spodek, 2010), and those that do, do soonly superficially (i.e., bright versus muted colors, realistic versus abstract pictures, preferences for computer graphics) (Jakobsdóttir et al., 1994). Since books with culturally relevant illustrations are not available to parents in the context of the UAE, this likely has a negative effect on their literacy socialization practices. Documenting culturally relevant preferences is the first step towards congruity.

\section{Visual Literacy: The Importance of Illustrations in Early Reading}

The use of illustrations in children's storybooks is not merely aesthetic but also educational. Studies on the impact of pictures on children's reading comprehension, discussion about the text, and critical thinking skills show that illustrations have a unique function in addition to their artistic value (Brenna, 2013; Brookshire et al., 2002; Feathers \& Arya, 2015; Greenhoot, et al., 2014; Orrantia et al., 2014). Indeed, the role of illustrations in children's storybooks is to provide a support for the text, especially for young children who cannot yet read conventionally.

Illustrations are also hypothesized to help children think more critically about the content of the text and enhance self-expression (House \& Rule, 2005). In accordance with cognitive theory, visuospatial mental representations augment reading comprehension (Van den Broek, 2010). As such, illustrations can facilitate memory formation and retrieval. Therefore, developing a visual literacy is thought to enhance children's meaning-making and motivation to read (Brooskhire et al., 2002; Liang \& Galda, 2015).

Preschool children focus on books' illustrations, and not on print(Evans \& Saint-Aubin, 2005; Justice, et al., 2005). This preference is unaffected by the spatial arrangement of the text (text in bubbles, text on bottom, etc.). Moreover, young children spend more time looking at illustrations that include richer, more complex and detailed drawings than they do forsimpler illustrations (Evans \& Saint-Aubin, 2005). It may, therefore, be concludedthat rich illustrations are particularly important for sustaining a child's attention during a storybook reading session (Greenhoot et al., 2014). This may be especially pertinent in settings where children are not used to being read to on a regular basis, are second-language learners, or with students who have trouble sustaining attention.

Moreover, illustrations influence both parent and child behaviors during joint reading. Illustrations promote greater active engagement, thereby eliciting more language from children (Greenhoot et al., 2014). Evans and Saint-Aubin's (2005) investigation confirmed that attention to illustrations versus print predominated comments and discussion about books by monitoring children's eye movements. The literature, therefore, calls for high-quality illustrations that inspire both children and parents to respond to children's storybooks(Brookshire et al., 2002; Feathers \& Arya, 2015).

\section{Parents' Preferences for Storybook Illustrations}

Parents' decision-making regarding children's story books is influenced by the illustrations. For example, one study asked parents of four-year olds to choose five books out of 14 presented to them representing various genres (Anderson, et al., 2001). Although secondary to content, parents did report that they selected books based on aesthetics and familiarity of illustrations. The concept of familiarity is grounded on the notion that people tend to interpret and respond to text based on their previous experience (Van de Broek, 2010). As a consequence, parent book selection has been suggested to be based on books that reflect their own experiences (Saracho \& Spodek, 2010).According to reader response theory (Rosenblatt, 1994), sociocultural factors influence people's reactions to text. Thus, it is worthwhile to examine the extent to which illustrations that mirror parents' cultural experiences impact their choices of storybooks for their children.

\section{The Present Study}

This study aims to inform sociocultural theories with regard to parents' behaviors related to family literacy and the home literacy environment. According to Tyler et al. (2008), 'cultural discontinuity is evidenced by the relative differences between cultural value-based behaviors exhibited at home and those exhibited at school' ( $p .281$ ). Therefore, we aimed to document a major factor for parents' decision-making about the storybooks they allow their young children to read - the illustrations. So far, few studies investigated the link between storybook 
preferences and race or ethnicity (Mohr, 2003; Stoodt-Hill \& Amspaugh-Corson, 2001).Addressing this gap, this is the first study known to the authors on the preferences of storybook illustrations within a Muslim, Arab population. More specifically, the present study examined the following research question: What are parents' preferences for children's storybook illustrations and why do they make these choices? This examination is a necessary prerequisite for quantifying cultural discontinuity (Tyler et al., 2008). The culture-specific information gleaned from this investigation may inform the limited local publishing industry, as well as the uninformed foreign children's storybook publishing industry, in the region. It also provides an empirical basis for teachers to inform their own culturally relevant practices with Muslim, Arab students.

\section{Method}

\section{Participants}

Participants were 118 parents, $87 \%$ mothers $(n=103)$ and $13 \%$ fathers $(n=15)$. The gender of the child which the parents were asked to reference in their answers was split equally, with fifty percent male and fifty percent female. Children almost evenly attended public and private schools (46\% and $54 \%$ respectively), which closely mirrors enrollment in the general population (Statistics Centre-Abu Dhabi, 2013). They were enrolled inkindergarten through grade 6 , with the majority of children $(n=88)$ between grades 1 and 4 . UAE schools require that children be 5 years of age by December 31st to enter kindergarten the following Fall, with compulsory education beginning from grade 1 . Confirming the degree of religiosity of the population would entail questioning that is considered to be offensive. Nevertheless, parents' religious affiliation is confidently presumed because accepting Islam is not only interwoven in the fabric of Emirati life, but is also a condition of citizenship.

To recruit participants for the present study, female research assistants were asked to nominate eligible persons. All research assistants were of the local culture and were students from a major public university in the UAE across two campuses in Abu Dhabi and Dubai. Eligibility criteria were (a) being a member of the local culture (i.e., UAE national) and (b) having a child enrolled in a private or public school in the UAE in kindergarten or grades 1 to 6 . Snowball sampling, a non-probability sampling technique (Given, 2008), was used, whereby research assistants nominated families that fulfilled the criteria and contacted them personally. These consisted of fellow students, family members, extended family members, and friends. Participants were then asked to nominate other potential participants. Snowball sampling allowed for a viable and culturally acceptable way to access the population, despite limitations in regard to the degree to which it may represent the target sample, discussed subsequently. Prior to data collection, the study was approved by the Institutional Review Board of the university and parents were briefed by research assistants regarding the confidentiality statement on the survey, since the data was anonymous.

\section{Materials}

A questionnaire, which included both multiple choice type questions and open-ended questions, was developed for the purpose of this study. The literature reviewed on storybook preferences of both parents and children was used as a basis for the questions (Anderson et al., 2001; House \& Rule, 2005; Mohr, 2003). Illustrations used were not taken from published storybooks, but rather developed for the measure and designed by an Emirati national to further ensure that those designs meant to be culturally sensitive were indeed a reflection of the local culture. Four illustrations included pairs of culturally congruent versus culturally incongruent images (illustration 1: landmarks in Abu Dhabi versus New York City skyline; illustration 2: family in traditional Emirati dress camping in the desert versus family in Western dress on a grassy farm; illustration 3: musicians in a majlis setting playing traditional instruments versus a musician in a concert hall playing Western instruments; illustration 4: a family in traditional dress sharing a meal versus a family in Western dress versus a family of rabbits). An additional four illustrations included foci on gender schemes (illustration 5: super heroes versus prince and princess), cartoon illustration styles (illustration 6: manga versus realistic versus unrealistic cartoon illustration styles), genre (illustration 7: cartoon fantasy versus realistic non-fiction), and humor (illustration 8: slapstick versus exaggeration versus absurdity).

In total, the questionnaire included 34 items that assessed parents' preferred content, 
genre, illustrations, and use of storybooks in reading and interacting with their child (Barza and von Suchodoletz 2016). However, this paper focuses on the results for favored illustrations only. Eight questions explicitly asked parents to choose between two or more illustrations and explain their preference, as described above. Three additional questions asked more generally about children's book preferences(e.g., 'Tell about one of your favorite children's books. Why is it your favorite?'). Three closed-ended survey questions also asked about detailed illustration proclivities. The questionnaire was available in paper and pencil format, in both English and Arabic.

\section{Procedure}

The data was collected during home visits and on the university campuses by trained student research assistants who were bilingual (English/Arabic) and Emirati, meeting the same ethno-cultural criteria for inclusion as the participants. Due to cultural norms, there are difficulties associated with gaining access to parents willing to participate in research. Therefore, utilizing trained research assistants of the same culture as the informants is most salient, especially for establishing rapport and gaining informed consent with the families(Jorgensen, 1989). This arrangement is also advantageous for reviewing interpretations of data subject to bias by principal investigators who are from a different (Western) cultural background, as is the case for this study (Denzin, 1989; Ezzy, 2013; Yin, 1994).

On average, the questionnaire was completed in 20 minutes. Although the questionnaire was originally designed with the idea that parents would read and mark their answers independently, many parents preferred that the research assistants read the questions aloud to them and record their answers. Therefore, most of the questionnaires ( $80 \%)$ were actually administered as a semi-structured interview. This accounts for why the majority were recorded in English, as most research assistants found themselves switching between both languages when administering the survey depending on the participants' level of language proficiency. Parents' responses on questionnaires conducted in Arabic $(n=13)$ were translated independently by two research assistants who then discussed the translations until a consensus was reached. A panel of six cultural referents consisting of two graduate students, two undergraduate students, one student advisor, and one professor (who were all Emirati nationals and bilingual in English/Arabic) were consulted to provide feedback on the accuracy of the analyses based on cultural norms and the content validity of the interpretation of the findings.

\section{Data Analysis}

The constant comparative method following Corbin and Strauss (2014) was used for the qualitative analysis, comprising open, axial, and selective coding. First, open coding was used and subsequently, connections were made between categories to identify patterns (Appendix A). For example, a parent stated that she would choose a book with an Abu Dhabi landmark depicted rather than the New York City skyline because she thought her child could recognize it more easily. This was coded as easily recognizable with a sub-code if indicated that it was easily recognizable by the child, parent or both. This recognizable quality is referred to as 'familiarity' in the literature and was indicated as a criteria for all four questions that pitted local versus foreign illustrations. Hence, the pattern of familiarity is coded, which was one explanation for selecting a storybook based on its illustrations. Next, patterns of responses that emerged from the data were generated into themes. For example, parents who chose familiar illustrations also emphasized a moral message. They indicated that simplicity of the illustrations enhanced their ability to determine the perceived moral message. Tied together, these ideas showed how parents stressed the importance of cultural transmission in joint storybook reading. This reduction strategy allowed the researchers to move from a description of the phenomena of interest to an understanding of them(Kolb, 2012). All participant data was analyzed despite the fact that saturation was reached, as patterns became redundant well before 100 responses were analyzed (Glaser \& Strauss, 2009).

All variables identified in the qualitative analyses were coded categorical. In a second step, two-way tables were used to determine relations between two categorical variables. The observed and expected frequencies in each combination of row and column categories were calculated using IBM $®$ SPSS Statistics Version 21. Chi ${ }^{2}$ statistics for two-way tables were used to determine the statistical significance of the observed relation. The stronger the 
relation between two categorical variables, the larger the $C h i^{2}$ value of the $C h i^{2}$ test. In addition, Phi values $(\Phi)$ were calculated to better interpret the strength of the relation. A perfect relation is indicated by a Phi value of 1 whereas a Phi value of 0 indicates that the variables are not related.

\section{Results}

Parents' preferences for children's storybook illustrations are reported in terms of illustrations selected with greatest frequency as well as the reasons parents gave for their choices. The presentation of the results is structured around the major themes that evolved from the data about what Muslim, Arab parents prefer in children's storybook illustrations. Both the content analysis and the Chi ${ }^{2}$ statistics are merged to support the findings.

Illustrations are Important in Parents' Decision-Making About Children's Storybooks, Although Secondary to Content

The relative importance of illustrations in parents' choices of storybooks was assessed. The majority of parents said they prioritize a storybook's content $(60 \%)$, over its illustrations when forced to choose between the two. However, when asked about what makes a good children's storybook, $83 \%$ of parents mentioned attractive illustrations. Illustrations were not a major factor overall when asked to describe their favorite children's books (7\%). Yet, the fact that about $25 \%$ of cited traditional folk tales have oral roots to this day, rather than being published storybooks, is important to note. Overall, Muslim, Arab parents attributed a substantial amount of importance to the attractiveness/quality of illustrations.

\section{Parents have a Strong Preference for Illustrations That Reflect their Culture and Values}

Respondents were given four opportunities to choose between two or more pictures that represented images congruent with their culture and those that represented images of foreign (Western) cultures. A synthesis of responses from all four prompts revealed a strong inclination towards pictures that are familiar, i.e., congruent with local culture and traditions (Figure 1). This includes local dress, landmarks, setting, and an emphasis on family togetherness. Among those who chose the more culturally congruent illustration shown in the third illustration (Figure 2a left), the majority stated that they did so because it showcased their local heritage (65\%).Similarly, those who chose a picture of a family in traditional Emirati dress over a family in Western clothing and a family of rabbit characters said they did so because 'it shows the Emirati family, traditions, culture and religion.'Another query depicts a local family in a desert setting in traditional dress versus a grassy family farm with characters in Western clothing. Over half $(61 \%)$ of respondents focused on how the culturally relevant illustration represented or helped children to learn about their own culture. Parents relayed that the focus on local heritage would educate their child, particularly 'to learn the traditions in the UAE" because it helps children to learn the heritage of our grandparents and keep it.'

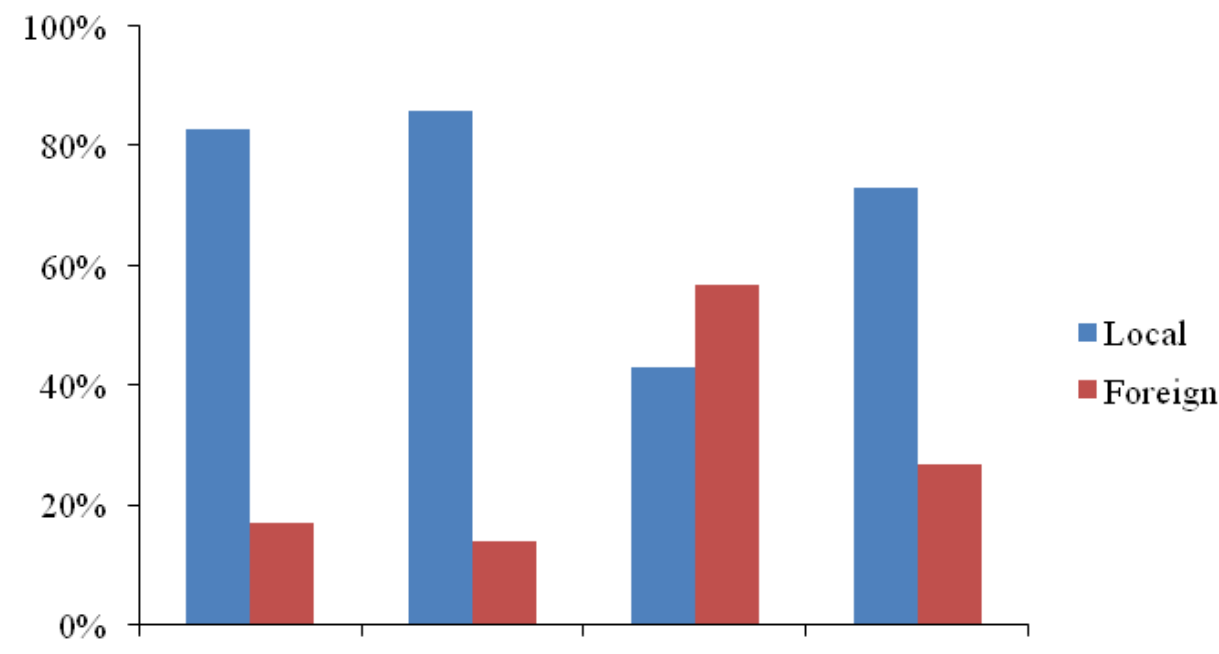

Illustration 1 Illustration 2 Illustration 3 Illustration 4

Figure 1. Percentage of parents who prefer illustrations that depict local versus foreign themes 


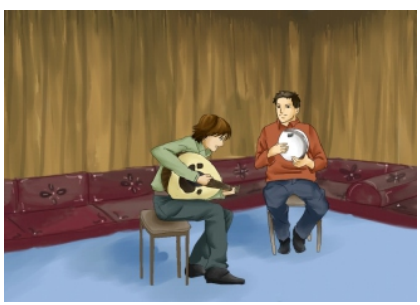

Musicians in a majlis setting playing

traditional instruments

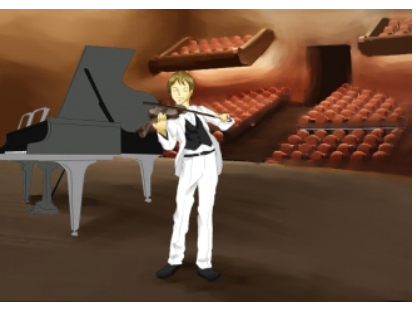

A musician in a concert hall playing

Western instruments

a) Illustration \# 3: Local versus foreign themes

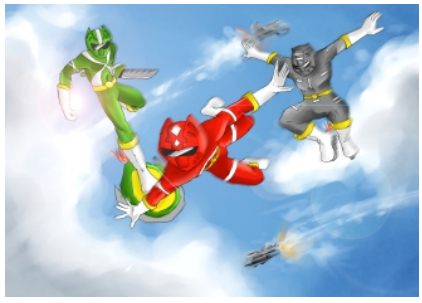

Superheroes (targeted for boys)

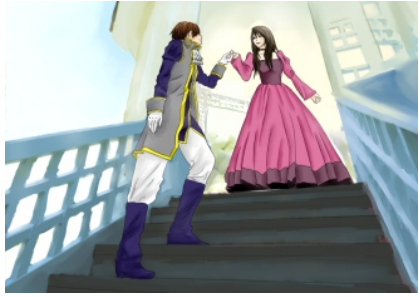

Prince and princess (targeted for girls)

b) Illustration \# 5: Illustrations featuring gender schemes

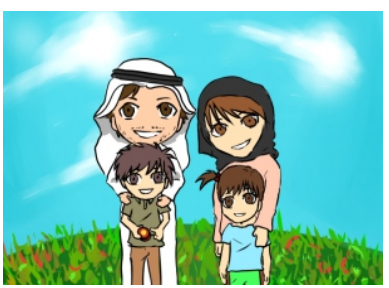

Manga style

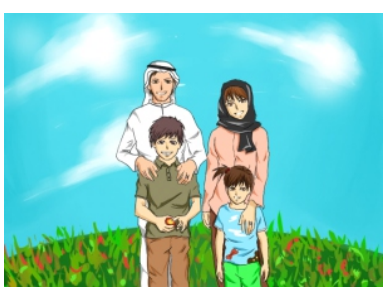

Realistic style

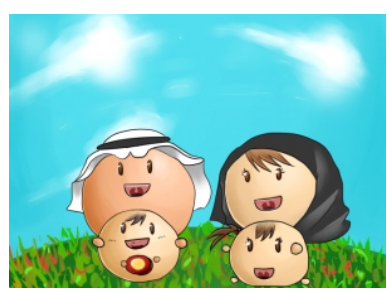

Unrealistic style

c) Illustration \# 6: Cartoon illustration styles

Figure 2. Examples of illustrations from the questionnaire that highlight parents' preferences for children's storybook illustrations

We note that the third illustration (Figure $2 a$ ) reflects a divergent result in comparison to the other three. Preferences for the foreign versus local/familiar illustration was more equivalent here. Based on the data, the divergent result may be explained by the fact that the pictures differed in other dimensions, besides that of familiarity. Those who chose the foreign illustration indicated a preference for the type of music depicted (piano and violin versus guitar and drums) and their child's preferences. Therefore, these other considerations may have confounded the variables the question intended to measure regarding familiarity.

\section{A Significant Minority of Religiously Conservative Parents Choose Books with Illustrations that Affirm, Rather than Contradict, their Religious Beliefs}

Although they represented a minority (6.4\%), some parents commented explicitly about the perceived cultural inappropriateness of either illustration shown in illustration 5 (Figure 2b), particularly the latter depicting a fairytale prince and princess. The objection was centered on the idea that it was a story about romance (e.g., 'I do not like romantic stories for children.') that is 'not from our culture, traditions and not from our religion'.

Similarly, six respondents (6\%) specifically stated that they did not approve of either drawing in the third illustration (Figure 2a) based on religious grounds, indicating that 'these pictures are not from our religion' and 'music is 'haram" which translates to 'sinful' or 'forbidden.' Noting that on the questionnaire a 'none' option indicating dislike of both pictures was not a choice offered is important. Therefore, those who refused both pictures either made a special note on the questionnaire to indicate so, or relayed their opinions to the research assistants, despite being prompted to make a choice. It is therefore likely that at least some, if not all, of those who 
indicated disapproval of either illustration also did so based on religious grounds even if they were not forthcoming as to their reasons why. Fifteen respondents (14\%) fall into this category and were vague in their explanations, such as'I don't like music' and 'I don't like any one of them.' If we posit that those who refused to approve either picture did so based on religious beliefs, even if they did not explicitly indicate so, then the percentage of respondents that fall into this category for this query rises from 14 to 20.

\section{Parents Prioritize Storybooks with Illustrations that Convey a Moral Message}

When scrutinizing storybook illustrations, the perceived moral of a story was often considered with responses like, 'Because it teaches the children how to deal with others kindly with a sensitive heart and emotions,' It has courage, power and teaches self-defense and cooperation,'and 'the second one [picture] teaches violence.' When asked about what makes a great children's storybook, about a third of parents $(n=32)$ indicated that they expect children's books to teach their child something.

Even when given a choice between illustrations intended to be humorous, $75 \%$ focused on how the picture could convey a moral message. Decision-making amongst humorous illustrations was based on respondents' perceptions of one picture as 'more interesting' or 'attractive' than the other, rather than humorous. Emirati parents found illustrations that do not plainly convey a moral message to be confusing, 'because the message is not clear.'

Although illustration 3 (Figure 2a) was intended to assess parents' preferences for familiarity, it also solicited responses that focused on their assessment of the story's moral. The first picture is more culturally congruent, including two musicians playing together in a casual setting. The second picture features a single musician playing a violin with a piano in the background of a concert hall. The number of musicians in the pictures seemed to have made a difference, since some chose the duo 'because it shows group work' or 'the gathering of friends' emphasizing that it 'encourages children to be more collaborative.'Hence, they inferred a possible moral message from every illustration provided. The relationship between moral messages and cultural values are difficult to separate. The present data suggests that of the total number of parents in the sample who prioritized storybooks that convey a moral message $(n=84)$ many also preferred illustrations that are familiar and culturally congruent $(79 \%, n=66)$.

\section{Parents Consider their Child's Preferences for Illustrations over Content, Although they Place Differing Values on this Based on Gender}

When asked to choose between four illustration styles, the second most frequently cited response, representing about $1 / 5$ of parents, was that their child would prefer the style indicated. Of those who considered their child's interests, some mentioned that their choice was based on 'what our children see on TV' and seem to enjoy. In addition, those who chose an illustration of animals versus people did so almost exclusively based on their child's preferences. Only about $10 \%$ referred specifically to the illustrations when asked to choose between two book covers intended to focus on a preferred genre. Some indicated that a fictional story is more attractive to children because it featured cartoon characters rather than photos. In contrast, few parents $(n=3)$ chose the more familiar picture of their capital city based on the perception that it would be more appealing to their children than a New York City skyline. Therefore, consideration of their child's preferences was most robust when asked about illustration styles rather than content.

The value parents placed on their child's preferences when deciding between storybooks was influenced by the child's gender. For those who chose the illustration targeted for girls (Figure 2b right), considering their child's preference was the least frequent reason given. Meanwhile, for those who chose the illustration targeted for boys (Figure $2 b$ left) the child's preference was the most salient variable considered. If illustrations portrayed people, parents had a significant preference for the same gender as their own child $\left(C h i^{2}=8.78[d f=1]\right.$, Phi = $.29, p<.01)$. Similarly, parents who had a preference regarding the main character's gender preferred a male character when their own child was a boy and a female character when their own child was a girl $\left(C h i^{2}=14.47[d f=2], P h i=.35, p<.01\right)$.

Parents Prefer Illustrations that are Familiar and Simple, which Allow them to Easily Determine Whether the Book is Culturally Appropriate for their Child

Overall, half of parents chose a particular cartoon illustration style because of its 'clear and 
realistic' depiction. When asked about what makes a good children's storybook, about a third cited simplicity in text and graphics second only to attractive and colorful illustrations. Few parents, less than $10 \%$, indicated that they preferred one genre over another because it either featured photos or cartoons. This consideration was overshadowed by their emphasis on whether they could easily identify what the book was about and determine its suitability (i.e., 'You can understand the content of the book from the title').Parents who preferred an informational genre significantly preferred illustration that are familiar and culturally congruent $\left(\mathrm{Chi}^{2}=16.89[\mathrm{df}=3], \mathrm{Phi}=.38, p<.01\right)$. Similarly, parents who prioritized a more realistic illustration style also preferred illustration that are familiar and culturally congruent $\left(\mathrm{Chi}^{2}=22.42[\mathrm{df}=4], \mathrm{Phi}=.44, \mathrm{p}<.01\right)$. If a book's title and illustrations were easy to understand, then parents could easily determine whether they approve of the storybook for their child. Books with ambiguous covers are more difficult to judge, there fore they are disregarded.

\section{Parents Prefer more Colorful, Realistic Illustration Styles}

The manga style and most realistic style of cartoon illustrations (Figure 2c left and middle) were equally preferred, representing a third of respondents each (35\%). The most unrealistic cartoon style (Figure $2 c$ right) was least preferred overall (10\%). Almost every respondent preferred bright colors for illustrations, as compared to muted colors or greyscale. These findings are consistent with those of Brookshire et al. (2002), whosefirst and third grade participants preferred brightly colored, realistic illustrations. Notably, parents preferred landscape (70\%) versus portrait (30\%) orientation.

\section{Discussion}

\section{Role of Illustrations in Storybook Selection}

Parents indicated that they rely on illustrations when assessing and evaluating the content of children's storybooks. In fact, Muslim, Arab parents preferred simplistic, realistic illustrations that facilitate ease of assessment. This may be attributed to the fact that visits to libraries and bookstores are not routine within the local culture of the UAE. Although literacy rates are high, the oral tradition is still quite strong within the UAE (Hourani, 2015). Therefore, parents might have focused on illustrations because they are not particularly adept at assessing the appropriateness of a storybook for their child based on other factors, such as readability and potential for stimulating discussion. An investment in parent education programs to this end would be beneficial (Delgado-Gaitan, 1991) in light of evidence that picture book reading interventions contribute to children's language development (Bus, Van ljzendoorn, \& Pellegrini, 1995). Illustrations play an important role in Emirati parents' choices for children's storybooks, although comparative studies are needed to infer whether or not they place more or less emphasis than parents in other populations.

\section{Informing Sociocultural Theory by Highlighting Cultural Discontinuities}

Cultural dissonance is evident when participants' strong preferences for storybook illustrations reflecting their national identity are compared with the few children's storybook offerings available in the cultural environment that fulfill this need. In order to be attractive to the population studied, illustrations must include characters who look and dress like themselves. With regard to the population of Emirati parents, illustrations should reflect the world renowned architecture of the bustling cities of Abu Dhabi and Dubai, the green and tranquil oasis of Al Ain, the traditional weekend barbecues at the Corniche parks, the bare footed impromptu football matches between buildings in the city, or the sands of the Empty Quarter. Illustrations that respectfully mirror the culture, and reflect the diversity of cultures within, show that the culture is valued. These efforts would also be consistent with recent initiatives for preserving the local culture, including a digital storytelling competition (Raven \& O'Donnell, 2010) and the Digital Emirates Project (Breslow, 2010). To the extent that children's storybooks are a medium for cultural transmission, results suggest that the cultural discontinuity underscored in this investigation permeates literacy socialization practices within the family.

A significant minority of Emirati parents, those who are more religiously conservative, rejected children's books based on illustrations that they perceive as contrary to the teachings of Islam. As directly indicated in this study, some specific objections include content related to playing music and romantic relationships. According to Islamic scholars, music is considered 
to be a grey area within Islam, and multiple interpretations of the Quran and Hadith are provided (Otterbeck, 2008; Otterbeck \& Ackfeldt, 2012). Some even consider the type of musical instrument played. One model divides Islamic music into three tiers representing legitimate (i.e., Quranic chants, call to prayer, wedding songs), controversial (i.e., vocal/instrumental improvisation, music of non-Islamic origins) and illegitimate (i.e., sensuous music) forms. Given the controversial nature of music within Islam, more conservative families may prefer to steer their children away from storybook content that would encourage it. This study confirms Otterbeck and Ackfeldt's (2012) contention of a 'dominance of a moderate, fairly tolerant, but still in part restrictive interpretation'(p.232).

Books with content related to romance, especially fairytales, dominate the shelves of most bookstores in the nation and are marketed towards young girls. Indeed, dating and physical affection before marriage is frowned upon in Emirati and other conservative Muslim cultures. It is not uncommon for couples to meet at their wedding ceremony for the first time, as arranged marriages are still the norm. Therefore, images of couples often seen in fairytales that depict a romance are considered as contrary to cultural norms and inappropriate for children. Participants' beliefs reverted to the roots of such tales, which were originally written for adults (Mdallel, 2010; Zipes, 2013). This glaring mismatch in cultures is reflected in parents' suspicion of books with more abstract or convoluted pictures that cannot be easily deciphered, in order to assess their content.

Although not directly assessed in this study, other content that would be culturally incongruent in this context could be presumed to include any inference to the consumption of alcohol and other foods forbidden in the Quran, graphic representations of God and all prophets, sexuality, and immodest clothing (Mdallel, 2010). Overall, about $10 \%$ of parents in the sample represented an ultra-conservative group that objected to the content of storybook illustrations on the grounds that it violates their religious beliefs. Cultural discontinuity is greatest for the subset of religiously conservative Muslims, who are a minority within their culture and differ even more prominently from the Western-influenced culture of schools.

Encouraging families to fill their homes and school libraries with books that include culturally relevant illustrations is not done at the expense of excluding other less familiar texts. We encourage this new emergence of culturally relevant children's storybooks as additive rather than subtractive. It is an enrichment of one's library for the purpose of encouraging family literacy in a way that compliments Emirati families' beliefs and not a censorship of all things foreign, which would decrease families' cultural capital. Including less familiar (i.e., foreign) literacy in families' homes also may help to reduce cultural dissonance for children when moving back and forth between their home's culture and their (more Western) school's culture.

\section{Transmission of Cultural Gender Schemes}

Children's preferences for a storybook's illustrations were considered by a minority of parents and only in relation to illustration style rather than content. This result, combined with the fact that parents deferred to boys' preferences, provides greater specificity in relation to the results of previous studies that showed that parents based their selections on their own interests only (Anderson et al., 2001; Saracho \& Spodek, 2010). Since participants prioritized a book's moral message, they see themselves as gatekeepers that need to carefully scrutinize the books their children are exposed to based on their assessment of the book's illustrations. Therefore, their preferences are prioritized over their child's.

When examined in light of common socialization practices, that parent decision-making was influenced by the child's gender is not surprising. Gender segregation in schools is common, and both traditional and religious practices define behavior along gender lines. Arguably, females are subject to greater social restrictions when compared to males, which is exemplified by cultural practices such as parents' or husband's permission required for international travel, and the expectation that females wear a shayla (head scarf) and abaya (loose black cloak). Additional expectations for more conservative families may include covering one's face in the presence of males, and older male siblings being given authority over their female siblings. Thus, the fact that parents gave more deference to their boys' preferences in choosing books as compared to their girls' is consistent with cultural norms. Different behavior expectations for boys and girls may have resulted in these gender findings (Beaman et al., 2006). Parents' preference of main characters of the same gender as their 
child also supports the underscored theme that illustrations convey a moral message, in the form of transmission of cultural gender schemes (Brody \& Hall, 2010), and that children's storybooks are an important influence, positively or negatively, on their child's behavior.

\section{Limitations and Future Directions}

A limitation of this study that needs to be considered when interpreting the results is the use of snowball sampling, which makes determining whether or not the sample was an accurate representation of the target population difficult (Given, 2008). For example, since the research assistants were university students, it is possible that their contacts were more highly educated or less conservative than the general population. The method of recruitment was used because it has been suggested to be a viable manner in which to collect data when working with populations that are difficult to access (Given, 2008). This recruitment technique is especially suited within the local culture of the UAE, where people are not easily persuaded to participate in research, especially when approached by strangers or non-natives.Moreover, the degree of variability between cultural groups has been debated (Gutierrez \& Rogoff, 2003). In an attempt to control for possible group effects, research assistants were selected from different tribal groups.

In addition, the study had a limited sample size and a broad age range of children included. Illustration preferences may possibly change, such that parents of children in grade 6 prefer a different illustration style or even place less emphasis on illustrations than parents of kindergarten students, because of the developmental age and children's reading abilities. Due to the fact that age groups were not equally represented in the sample, and because of the crosssectional nature of the data, this could not be addressed in the present study. Similarly, the small number of parents falling into the category of a conservative religious minority limits the interpretation of the findings regarding the preferences of these parents. Nevertheless, the results present an opportunity for investigating changes in family traditions and trends among Emirati nationals due to modernization and Western influences in the nation.

Finally, actual book selection and reading behaviors among parents and children were not observed. It is assumed that reported preferences for these images would be carried through into actual decisions and practices with books designed and illustrated by authors and illustrators. This was not possible to do because of the few storybooks in the UAE that reflect the national identity. Self-report instruments also assume that parents would have some metacognitive awareness about their own criteria for decision-making. Further, the investigation focused on illustration choice, but not the degree to which parents' choices influenced the quantity and quality of joint reading (Kraaykamp, 2003). Data on families' home libraries was also not collected. Book selection in a more natural setting with subsequent interviews, and the inclusion of additional data targeting the home literacy environment, would allow for confirmation and expansion of results.

\section{Conclusion}

This study revealed the characteristics of culturally relevant children's literature as depicted in storybook illustrations for Muslim, UAE nationals. The interconnectedness between religion and culture within a Muslim nation is reinforced by the results of this study. Major moral tenets of Islam are considered by parents to be a reflection of the culture. As such, parents expected them to be reflected in the illustrations of chosen children's storybooks. The UAE is a new nation and a society that has been pushed to change rapidly, influenced by many Western and non-Western cultures. Nevertheless, its tribal and religious roots still ground the culture in a core set of beliefs and practices that influence parent behaviors. Recent events have also ignited conversations about how the Muslim worldview impacts print media in general. Emirati families closely link literacy and identity formation, as suggested by Moje and Luke (2009) who conclude in their review 'literacy-and-identities research may be important - even central - to enhancing educational opportunity for all people' (pp. 434). Our results show howparents prefer culturally relevant illustrations, that they are aware of what illustrations are and are not considered to be congruent with the culture, and how gender socialization significantly affects their choices. This, no doubt, affects the quantity and quality of family literacy activities in the home, which are so important for assuring the motivation and reading achievement of children.

\section{Funding}

This work was supported by Zayed University; under Grant R10007. 


\section{Appendix A}

\section{Sequence of coding (example)}

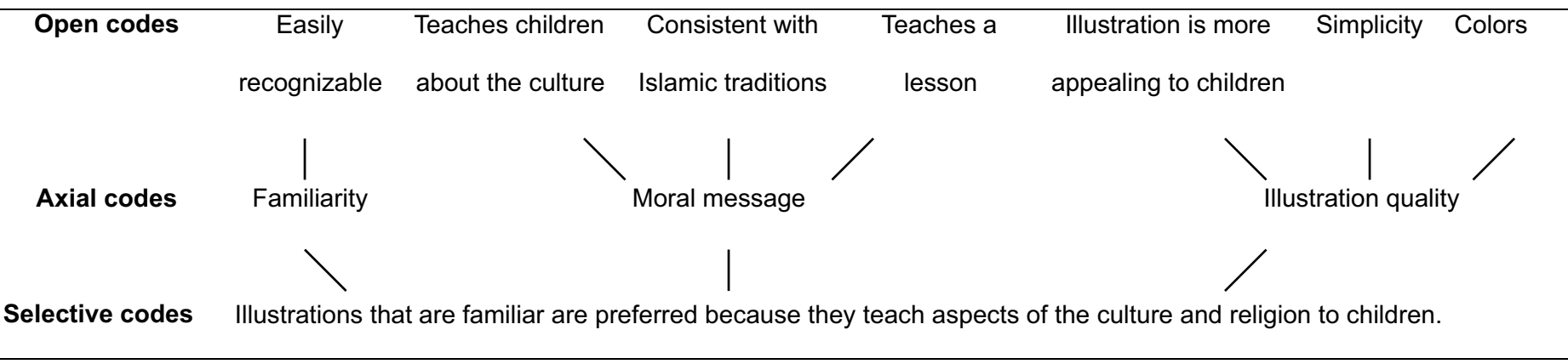




\section{References}

Anderson, J., Anderson, A., Shapiro, J., \& Lynch, J. (2001). Fathers' and mothers' book selection preferences for their four year old children. Reading Horizons, 41(4), 189-210.

Badri, M., Mourad, T., Ferrandino, V., Makki, R., Sayari, S., \& Messaikeh, N. (2011). Measuring job satisfaction among teachers in Abu Dhabi schools: Design and testing differences. Abu Dhabi: Abu Dhabi Education Council.

Barza, L. 2014. Home Literacy Practices of Three Ethno-cultural Groups in the U.S.: A Collective Case Study on Culture and Support for Early Reading. International Review of Contemporary Learning Research, 3(1): 35-49.

Barza, L. 2017. Empowering Culturally Foreign Teachers by Fostering Cultural Competence. In Teacher Professional Knowledge and Development for Reflective and Inclusive Practices, edited by I. H. Amzat and N. P. Valdez, New York: Routledge.

Barza, L. and A. von Suchodoletz. 2016. Home Literacy as Cultural Transmission: Parent Preferences for Shared Reading in the United Arab Emirates. Learning, Culture and Social Interaction, 11: 142-152.

Beaman, R., Wheldall, K., \& Kemp, C. (2006). Differential teacher attention to boys and girls in the classroom. Educational Research Review, 58(3), 339-366.

Bourdieu, P., \& Passeron, J. C. (1990). Reproduction in education, society and culture (Vol. 4). London: Sage.

Boykin, A. W., \& Cunningham, R. T. (2001). The effects of movement expressiveness in story content and learning context on the analogical reasoning performance of African American children. Journal of Negro Education, 70, 72-83.

Brenna, B. (2013). How graphic novels support reading comprehension strategy development in children. Literacy, 47(2), 88-94.

Breslow, H. (2010). New Media Use in the Production of National Identity and the Preservation of National History: The Digital Emirates Project. Retrieved from http://www.inter-disciplinary.net/wpcontent/uploads/2010/02/breslowcoutinhopaper.pdf

Brody, L. R., \& Hall, J. A. (2010). Gender, emotion, and socialization. In J. C. Christer \& D. R. McCreary (eds.), Handbook of gender research in psychology: Vol. 1. Gender research in general and experimental psychology (pp. 429-454). New York, NY: Springer.

Brookshire, J., Scharff, L. F., \& Moses, L. E. (2002). The influence of illustrations on children's book preferences and comprehension. Reading Psychology, 23(4), 323-339.

Burchinal, M., McCartney, K., Steinberg, L., Crosnoe, R., Friedman, S. L., McLoyd, V., \& Pianta, R. (2011). Examining the Black-White achievement gap among low-income children using the NICHD study of early child care and youth development. Child Development, 82(5), 1404-1420.

Bus, A. G., Van ljzendoorn, M. H., \& Pellegrini, A. D. (1995). Joint book reading makes for success in learning to read: A meta-analysis on inter generational transmission of literacy. Review of Educational Research, 65(1), 1-21.

Chapman, M., Filipenko, M., McTavish, M., \& Shapiro, J. (2007). First Graders' Preferences for Narrative and/or Information Books and Perceptions of Other Boys' and Girls' Book Preferences. Canadian Journal of Education/Revue Canadienne de l'Éducation, 30(2), 531-553.

Chick, K. A., \& Heilman-Houser, R. A. (2000). Children's literature choices: Gender stereotypes prevail. Pennsylvania Reading: Journal of the Keystone State Reading Association, 1, 3-13.

Cochran-Smith, M. (2001). Learning to teach against the (new) grain. Journal of Teacher Education, 52(1), 3.

Coleman, J. S. (1988). Social capital in the creation of human capital. American Journal of Sociology, $94,95-120$

Corbin, J., \& Strauss, A. (2014). Basics of qualitative research: Techniques and procedures for developing grounded theory. London: Sage.

Delgado-Gaitan, C. (1991). Involving parents in the schools: A process of empowerment. American Journal of Education, 100(1), 21-46.

Denzin, N. K. (1989). The research act ( $3^{\text {rd }}$ ed.). Englewood Cliffs, NJ: Prentice Hall.

Evans, M. A., \& Saint-Aubin, J. (2005). What children are looking at during shared storybook reading: 
Evidence from eye movement monitoring. Psychological Science, 16(11), 913-920.

Ezzy, D. (2013). Qualitative analysis. London: Routledge.

Feathers, K. M., \& Arya, P. (2015). Exploring young children's use of illustrations in a picture book. Language and Literacy, 17(1), 42-62.

Freire, P. (1973). Education for critical consciousness. New York, NY: The New Press.

Gay, G. (2000). Culturally responsive teaching. New York, NY: Teachers College Press.

Given, L. M. (2008) (Ed.), The SAGE Encyclopedia of qualitative research methods. (Vol. 2). Thousand Oaks, CA: Sage.

Glaser, B. G., \& Strauss, A. L. (2009). The discovery of grounded theory: Strategies for qualitative research. Piscataway, NJ: Transaction Publishers.

Goldenberg, C. N.(1989). Parents' effects on academic grouping for reading: Three case studies. American Educational Research Journal, 26(3), 329-352.

Goldenberg, C., Reese, L., \& Gallimore, R. (1992). Effects of literacy materials from school on Latino children's home experiences and early reading achievement. American Journal of Education,100(4), 497-537.

Greenhoot, A. F., Beyer, A. M., \& Curtis, J. (2014). More than pretty pictures? How illustrations affect parent-child story reading and children's story recall. Frontiers in Psychology, 5, 738.

Gutierrez, K. D., \& Rogoff, B. (2003). Cultural ways of learning: Individual traits or repertoires of practices. Educational Researcher, 32(5), 19-25.

Hale, L., Berger, L. M., LeBourgeois, M. K., \& Brooks-Gunn, J. (2011). A longitudinal study of preschoolers' language-based bedtime routines, sleep duration, and well-being. Journal of Family Psychology, 25(3), 423.

Hauser-Cram, P., Sirin, S. R., \& Stipek, D. (2003). When teachers' and parents' values differ: Teachers' rating of academic competence in children from low-income families. Journal of Educational Psychology, 95, 813-820.

Hourani, R. B. (2015). Folktales, Children's Literature and National Identity in the United Arab Emirates. The Looking Glass: New Perspectives on Children's Literature, 18(1).

House, C. A. \& Rule, A.C. (2005). Pre-schoolers' ideas of what makes a picture book illustration beautiful. Early Childhood Education Journal, 32(5), 283-290.

Howard, T. C. (2010). Why race and culture matter in schools: Closing the achievement gap in America's classrooms. Multicultural Education Series. New York, NY: Teachers College Press.

Jakobsdóttir, S., Krey, C. L., \& Sales, G. C. (1994). Computer graphics: Preferences by gender in grades 2, 4, and 6. The Journal of Educational Research, 88(2), 91-100.

Janson, T. (2012). Imaging Islamic Identity: Negotiated Norms of Representation in British-Muslim Picture Books. Comparative Studies of South Asia, Africa and the Middle East, 32(2), 323-338.

Jordan, C., Tharp, R. G., \& Vogt, L. (1985). Compatibility of classroom and culture: General principles with Navajo and Hawaiian instances. (Working paper). Honolulu, HI: Kamehameha Schools/Bishop Estate, Center for Development of Early Education.

Jorgensen, D. L. (1989). Participant observation: A methodology for human studies. Newbury Park, CA: Sage.

Justice, L. M., Skibbe, L., Canning, A., \& Lankford, C. (2005). Pre-schoolers, print and storybooks: An observational study using eye movement analysis. Journal of Research in Reading, 28(3), 229-243.

Kolb, S. M. (2012). Grounded theory and the constant comparative method: Valid research strategies for educators. Journal of Emerging Trends in Educational Research and Policy Studies, 3(1), 83-86.

Kraaykamp, G. (2003). Literary socialization and reading preferences. Effects of parents, the library, and the school. Poetics, 31, 235-257.

Ladson-Billings, G. (1994). The dreamkeepers: Successful teachers of African-American children. San Francisco, CA: Jossey-Bass Publishers.

Lewis, C., \& del Valle, A. (2009). Literacy and identity: Implications for research and practice. In L. Christenbury, R. Bomer, \& P. Smagorinsky (Eds.), Handbook of adolescent literacy research(pp. 307-322). New York: Guilford. 
Liang, L. A., \& Galda, L. (2015). Reading text and image. In D. A. Wooten \& B. E. Cullinan (Eds.), Children's literature in the Reading Program: Engaging young readers in the 21st century (pp. 83-95). Newark, DE: International Literacy Association.

Mdallel, S. (2010). The Sociology of Children's Literature in the Arab World. The Looking Glass: New Perspectives on Children's Literature, 8. Retrieved from http://the-looking-glass.net /index.php /tlg/article/view/177/176

Mohr, K. A. J. (2003). Children's choices: A comparison of book preferences between Hispanic and nonHispanic first graders. Reading Psychology, 24(2), 163-176.

Moje, E. B., \& Luke, A. (2009). Literacy and identity: Examining the metaphors in history and contemporary research. Reading Research Quarterly, 44(4), 415-437.

Moll, L. C., \& Gonzalez, N. (1994). Lessons from research with language-minority children. Journal of Reading Behavior, 26(4), 439-456.

Ndura, E. (2004). ESL and cultural bias: An analysis of elementary through high school textbooks in the Western United States of America. Language, Culture and Curriculum, 17(2), 143-153.

Nieto, S. (1999). The light in their eyes: Creating multicultural learning communities. New York, NY: Teachers College Press.

Orrantia, J., Múñez, D., \& Tarín, J. (2014). Connecting goals and actions during reading: The role of illustrations. Reading and Writing, 27(1), 153-170.

Otterbeck, J. (2008). Battling over the public sphere: Islamic reactions to the music of today. Contemporary Islam, 2, 211-228.

Otterbeck, J., \& Ackfeldt, A. (2012). Music and Islam. Contemporary Islam, 6, 227-233.

Parsons, E. C., Travis, C., \& Simpson, J. (2005). The Black cultural ethos, students' instructional context preferences, and student achievement: An examination of culturally congruent science instruction in the eighth grade classes of one African American and one Euro-American teacher. Negro Educational Review, 56, 183-204.

Raven, J., \& O'Donnell, K. (2010). Using digital storytelling to build a sense of national identity amongst Emirati students. Education, Business and Society: Contemporary Middle Eastern Issues, 3, 201-217.

Rosenblatt, L. M. (1994). The reader, the text, the poem: The transactional theory of the literary work. Carbondale, IL: SIU Press.

Saracho, O. N., \& Spodek, B. (2010). Families' selection of children's literature books. Early Childhood Education Journal, 37(5), 401-409.

Schudson, M. (1989). How culture works. Theory and Society, 18, 153-180.

Sénéchal, M., \& LeFevre, J. A. (2002). Parental involvement in the development of children's reading skill: A five-year longitudinal study. Child Development, 73(2), 445-460.

Statistics Centre-Abu Dhabi. (2013). Statistical Yearbook of Abu Dhabi 2013. Retrieved from https://www.abudhabi.ae/cs/groups/public/documents/publication/ywrf/mtix/ edisp/ad_121297.pdf

Stoodt-Hill, B. D., \& Amspaugh-Corson, L. B. (2001). Children's literature: Discovery for a lifetime (2nd ed.). Upper Saddle River, NJ: Merrill Prentice Hall.

Sue, D. W. (2004). Whiteness and ethnocentric monoculturalism:Making the 'invisible' visible. American Psychologist, 59(8), 761-769.

Sue, D. W., \& Sue, D. (2003). Counseling the culturally diverse: Theory and practice (4th ed.). New York, NY: Houghton Mifflin.

Tharp, R. G. (1982). The effective instruction of comprehension: Results and description of the Kamehameha Early Education Program. Reading Research Quarterly,17(4) 503-527.

Tyler, K. M., Boykin, A. W., \& Walton, T. R. (2006). Cultural considerations in teachers' perceptions of student classroom behavior and achievement. Teaching and TeacherEducation, 22(8), 998-1005.

Tyler, K. M., Uqdah, A. L., Dillihunt, M. L., Beatty-Hazelbaker, R., Conner, T., Gadson, N., ... Stevens, R. (2008). Cultural discontinuity: Toward a quantitative investigation of a major hypothesis in education. Educational Researcher, 37(5), 280-297.

Van den Broek, P. (2010). Using text in science education: Cognitive processes and knowledge representation. Science, 328(5977), 453-456. 
Vogt, L. A., Jordan C., \& Tharp R. G. (1987). Explaining school failure, producing school success: Two cases. Anthropology and Education Quarterly, 18(4), 276-286.

Webb-Johnson, G. C. (2003). Behaving while Black: A hazardous reality for African American learners. Beyond Behavior, 12, 3-7.

Wortham, S. (2006). Learning identity: The joint emergence of social identification and academic learning. Cambridge, England: Cambridge University Press.

Yin, R. K. (1994). Case study research: Design and methods (2nd ed.). Newbury Park, CA: Sage.

Zipes, J. (2013). When dreams came true: Classical fairy tales and their tradition. New York, NY: Routledge. 